\title{
Spinal Injuries in a Tertiary Care Referral Center of Western Nepal
}

\author{
Devkota P, $^{1^{*}}$ Manandhar HK, ${ }^{1}$ Khadka PB ${ }^{1}$ \\ ${ }^{\perp}$ Department of Orthopaedics and Trauma Surgery, Kaski Sewa Hospital and Research Center, \\ Hospital Chowk, Pokhara, Nepal
}

\author{
* Corresponding Author: \\ Dr Pramod Devkota, MBBS MS(Ortho) \\ Department of Orthopaedics and Trauma Surgery \\ Kaski Sewa Hospital and Research Center \\ Hospital Chowk, Pokhara, Nepal. \\ E-mail: pramodcd@yahoo.com

\section{Citation} \\ Devkota P, Manandhar HK, Khadka PB. Spinal Injuries in \\ a Tertiary Care Referral Center of Western Nepal. Nepal \\ Journal of Medical sciences 2013;2(2):156-9.
}

\begin{abstract}
Background: Spinal injury is a devastating condition often affecting young and healthy individuals around the world. This devastating injury not only creates enormous physical and emotional cost to individuals but also gives tremendous financial burden to the society. We evaluate the demography, types and causes of the spinal injuries and their management in patients admitted in a hospital.
\end{abstract}

Methods: Medical records of 45 patients who were presented with spinal injuries in a year were analyzed. The age, sex, mode of injury, sites, types and level of injury, hospital stay, and treatment given were analyzed. Frankel grading was used for the evaluation of the neurological deficits.

Results: The mean age of the patient was 47.5 years (range 19 - 78). Male patients were $60 \%(n=27)$ and female $40 \%(n=18)$. There were $42.2 \%$ $(\mathrm{n}=19)$ patients with $\mathrm{E}$ grade, $24.4 \%(\mathrm{n}=11)$ patients with $\mathrm{C}$ grade, $20 \%$ $(n=9)$ patients with $D$, three $6.6 \%(n=3)$ patients with $A$ and $B$ grades each of patients according to Frankel grade. Lumbar spine was the commonest site of injury. The most common cause of injury was fall, followed by road traffic accidents (RTA) and others. Nineteen patients were treated conservatively, 16 were operated, five patients were referred to other centers due to various reasons and the other five patients were discharged on their request.

Conclusions: Spinal injuries are one of the rapidly growing injuries in our society and the commonest mode of injury was fall. The majority of patients were from the hilly areas.

Keywords: Fall injury; Frankel score; spinal injury; vertebral fracture patient. ${ }^{1}$ Spinal injuries include injuries to the spinal column and spinal cord. Acute injuries of the spinal column and spinal cord are among the most causes of severe disability and death after trauma. ${ }^{2}$

Spine injury prevalence in trauma patients is $6 \%$ and among all the spinal fractures, $90 \%$ occur between T- 11 and L-4 vertebra. ${ }^{3}$ Spinal injury frequently involves multiple, noncontiguous 


\section{Original Article | Devkota P, et al. Spinal injuries in western Nepal}

vertebral levels. Multilevel spine fractures are present in 15$20 \%$ of spine-injury patients. ${ }^{4}$ The annual incidence of spinal column injuries ranges from 19-88/100,000. ${ }^{5}$ The incidence of spinal cord injury (SCI) is $15-50$ per million per year. ${ }^{6}$ The prevalence of SCI is $480-831$ per million. ${ }^{7}$ The incidence of spinal injuries in the developing countries is not known but the incidence is steeply rising. ${ }^{8}$

The exact data of the spine trauma patients is not available in our country but the incidence of this fatal injury is increasing. We report our experience of spinal injuries in a tertiary level referral center of the western region of Nepal in a year period of time.

\section{Methods:}

This is a retrospective study carried out in the Department of Orthopaedic and Trauma Surgery of Gandaki Medical College, Teaching Hospital (Charak Hospital), Pokhara, Nepal. From October 2010 to September 2011, total of 45 patients with spinal injuries were included in this study. Necessary permission was taken from the ethical committee of the hospital.

The age, sex, mode of injury, site and level of injury, hospital stay, treatment given were analyzed. The neurological deficits were evaluated according to the Frankel ${ }^{9}$ grading system. Mechanism of injury was classified as road traffic accident (RTA), fall (from height and tree), and others. The fracture types were classified as burst fracture, compression fracture and fracture dislocation. All the patients admitted with injuries of spine with age more than eighteen years old were included in this study. Those patients who had spinal pathology like infection, tuberculosis (TB), metastasis and malignancies were excluded. Also excluded were who had spinal deformities like spondylolysis, spondylolisthesis, scoliosis, kyphosis and degenerative changes. The patients aged less than eighteen years old were also excluded. Statistical analysis was done using Excel.

\section{Results}

The age ranges from 19 to 78 years with the mean age being 47.5 years. The age distribution of patients is shown in Table 1 .

Table 1: Age distribution of the patients with spinal injuries

\begin{tabular}{lll}
\hline Age Group (years) & No of patients & Percentages \\
\hline Below 30 & 9 & 20 \\
$31-40$ & 5 & 11.1 \\
$41-50$ & 13 & 28.8 \\
$51-60$ & 8 & 17.7 \\
Above 61 & 10 & 22.2 \\
\hline
\end{tabular}

Male patients were 60\% $(n=27)$ and female $40 \%(n=18)$. The neurological status were assessed using Frankel ${ }^{9}$ score and there were $42.2 \%(n=19)$ patients with $E$ grade, $24.4 \%$ $(n=11)$ patients with $C$ grade, 20\% $(n=9)$ patients with D, 6.6\% $(n=3)$ patients with $A$ and $B$ grades each. The most common fractures were in the lumbar region 55.5\% $(n=25)$, followed by dorsal spine $26.6 \%(n=12)$ and cervical spine $17.7 \%(n=8)$. The most number of patient sustained fracture was L2 level.

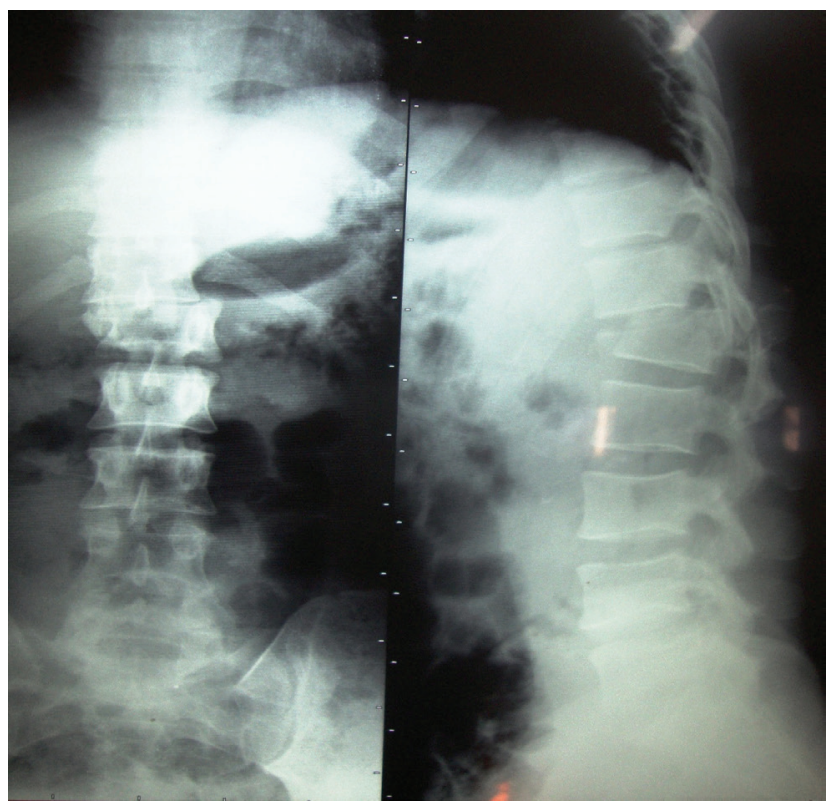

Figure 1 : Fracture dislocation of first lumbar (L1) vertebra of 30 year old male

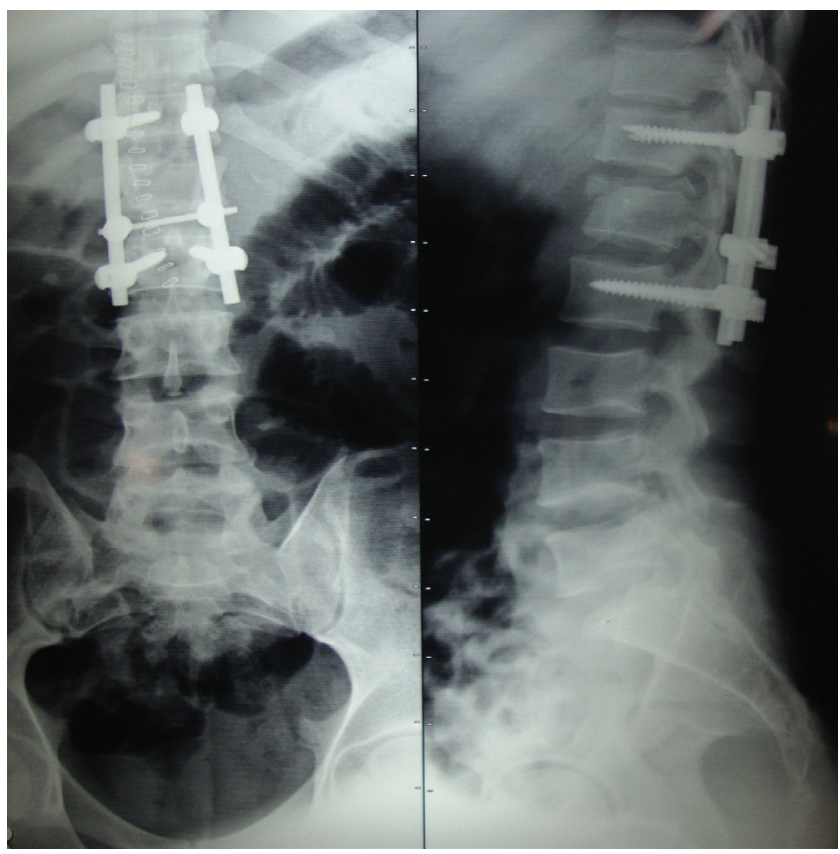

Figure 2: postoperativex-ray after pedicle screw, rod fixation

The most common cause of injury was fall (57.7\%), followed by road traffic accident $\{$ RTA $(33.3 \%)\}$ and others $(4.8 \%)$. Compression fracture $(42.2 \%)$ was the commonest 
followed by burst (35.5\%) and fracture-dislocation (22.2\%). Among the fall injuries, $22.2 \%(n=10)$ of patients from tree. Sixteen patients $(35.5 \%)$ were operated at this centre. All the victims of fall injuries were from the hilly areas around Pokhara city. The posterior stabilization was done by using posterior instrumentation of pedicle screws and rods. Nineteen $(42.2 \%)$ patients were treated conservatively; five $(11.1 \%)$ patients were referred to other centers due to various reasons and the other five patients were discharged on the request of patient or patient party.

The mean follow up period was 10.30 months (range 7-21) after the injury. The mean arrival time to the hospital was 4.60 days (range 1-9) and the mean hospital stay was 18.76 days (range 11-27). All the Grade D patients and six Grade $\mathrm{C}$ patients progressed to Grade E, five Grade C patients progressed to Grade D and no progression observed in Grade A patients. Some progression was noted in Grade B patients but not progressed to Grade C. No significant differences in the neurological improvement between the conservative and operative patients.

\section{Discussions:}

The mean age of the patients was 47.5 years which is quiet young ages of the patient. Spinal injuries were significantly higher in male patient than their opposite sex counterpart. The mode of injury was fall (from height and tree) in 57.7\% $(n=26)$ patients and all these patients are from the hilly region around the city. The mean arrival time in hospital was 4.60 days and the mean hospital stay time was 18.76 days. At least one grade of improvement was noted in Grades D, C but not significant in Grades A, B.

Fall is the major cause of spinal injuries in the developing countries followed by the RTAs with the majority of victims are young in the productive ages and this has been shown by this and other studies. ${ }^{10,11}$

The most common type of fracture is compression followed by burst and fracture dislocation as the commonest mode of injury is fall which is similar reports from other developing countries. $^{11,12}$ In our study, the incidence of the spinal injuries in the male patients was clearly higher than the female which other studies have also reported. ${ }^{10-12}$

In this study, the thoraco-lumbar junction is the commonest site of injury and lumbar spine fracture was more than others which is similar to other studies. ${ }^{12-14}$ The arrival period of time to the hospital after the injury were late in the developing countries and the mean arrival time to the hospital was 4.60 days after the injury which is comparable with other published data from the developing countries. ${ }^{11,12,14}$

Nineteen $(42.2 \%)$ patients were treated conservatively and sixteen patients $(35.5 \%)$ were operated at this centre. At least one grade of improvement was noted in Grades D, C but not significant in Grades A, B. No significant differences were noted in the neurological improvement between the conservative and operative patients which is compatible with other studies. ${ }^{15-17}$

\section{Conclusions:}

Spinal injuries are one of the rapidly growing injuries in our society. Due to the geographical nature of our country, the commonest mode of injury was fall from the height and tree. The majority of patients were from the hilly areas and young in the productive age.

\section{References:}

1. Licina P, Nowitzke AM. Approach and considerations regarding the patient with spinal injury. Injury 2005;36:B2-12.

2. Yousefzadeh CS, Safaee M, Alizadeh A, et al. Epidemiology of traumatic spinal injury: a descriptive study. Acta Med Iran 2010;48:308-11.

3. Riska EB, von Bonsdorff H, Hakkinen S, et al. Primary operative fixation of long bone fractures in patients with multiple injuries. J Trauma 1977;17:111-21.

4. Vaccaro AR, An HS, Lin S, et al. Noncontiguous injuries of the spine. J Spinal Disord 1992;5:320-9

5. Hu R, Mustard CA, Burns C. Epidemiology of incident spinal fracture in a complete population. Spine (Phila Pa 1976) 1996;21:492-9.

6. Wyndaele M, Wyndale JJ. Incidence, prevalence and epidemiology of spinal cord injury: what learns a worldwide literature survery? Spinal Cord 2006;44:5239.

7. Spinal Cord Injury Information Network [Internet]. [updated 2009]. Available from:http://www.spinalcord. uab.edu

8. Raja IA, Vohra AH, Ahmad M. Neurotrauma in Pakistan. World J Surg 2001;25:1230-7.

9. Frankel HL, Hancock DO, Hyslop G, et al. The value of postural reduction in the initial management of closed injuries of the spine with paraplegia and tetraplegia.I. Paraplegia 1969;7:179-92. 
Original Article | Devkota $\mathrm{P}$, et al. Spinal injuries in western Nepal

10. Khan I, Nadeem M, Rabbani ZH. Thoracolumbar junction injuries and their treatment management with pedicle screws. J Ayub Med Coll Abbottabad 2007;19:7-10.

11. Qureshi MA, KhaliqueAB, Pasha IF, et al. Epidemiology of non-disaster spinal injuries at a spine unit. J Coll Physicians Surg Pak 2010;20:667-70.

12. Raja RA. Management of thoracolumbar spine injuries at a tertiary care hospital.J Ayub Med Coll Abbottabad 2010;22:171-5.

13. Freslon M, Bouaka D, Coipeau P, et al.Thoracolumbar fractures. Rev Chir Orthop Reparatrice Appar Mot 2008;94:S22-35.
14. Roohi SA, Naicker AS, Shukur MH, et al. Spinal injuries in a level-one trauma centre: a demographic study. Med J Malaysia 2006;61:30-5.

15. Gertzbein SD, Court-Brown CM, Marks P, et al. The neurologic outcome following surgery for spinal fractures. Spine (Phila Pa 1976) 1988;13:641-4.

16. McLain RF, Sparling E, Benson DR. Early failure of short- segment pedicle instrumentation for thoracolumbar fractures. A preliminary report. J Bone Joint Surg Am 1993;75:162-7.

17. Riebel GD, Yoo JU, Fredrickson BE, et al. Review of Harrington rod treatment of spinal trauma. Spine (Phila Pa1976) 1993;18:479-91. 